\title{
POLYPROPYLENE-BASED WOOD-PLASTIC COMPOSITES: EFFECT OF USING A COUPLING AGENT DERIVED FROM A RENEWABLE RESOURCE
}

\author{
Matheus Poletto ${ }^{1, \mathrm{~s}}$
}

\begin{abstract}
In this work, post-consumer polypropylene and wood flour from Pinus elliottii were used to produce wood plastic composites. The effect of polypropylene grafted with itaconic acid used as a coupling agent on mechanical properties, thermal stability and morphology of the composites was investigated and compared with the composite developed with polypropylene grafted with maleic anhydride, commonly used as coupling agent in wood plastic composites. Composites with $30 \mathrm{wt} \%$ of wood flour and $2 \mathrm{wt} \%$ of coupling agent were produced in a co-rotating twin-screw extruder and after were injection molded. The mechanical properties showed that flexural strength improved on $29 \%$ and $35 \%$ with addition of polypropylene grafted with itaconic acid and polypropylene grafted with maleic anhydride respectively, when compared with the wood plastic composites without coupling agent. On the other hand, the incorporation of polypropylene grafted with itaconic acid does not change the impact strength values significantly. Additionally, the temperature corresponding to $3 \mathrm{wt} \%$ of weight loss determined by thermogravimetry for composites with polypropylene grafted with itaconic acid increased by $14^{\circ} \mathrm{C}$ when compared with wood plastic composites without coupling agent, while addition of polypropylene grafted with maleic anhydride increased approximately $6^{\circ} \mathrm{C}$ the composite thermal stability. A morphological study revealed the positive effect of the polypropylene grafted with itaconic acid on the interfacial bonding of recycled polypropylene and wood flour.
\end{abstract}

Keywords: Flexural strength, mechanical properties, Pinus elliottii, thermal stability, wood flour.

\section{INTRODUCTION}

Wood plastic composites (WPC) are obtained as a combination of a thermoplastic resin and wood fiber (or natural fiber), together with varying amounts of additives (Fabiyi and McDonald 2014). The natural fibers offer a combination of attractive properties such as low density, high specific strength and modulus, renewability, biodegradability, wide availability and low cost (Khonsari et al. 2015, Habibi et al. 2008). The main disadvantage of using natural fibers in wood plastic composites is the low compatibility between the hydrophilic character of the polar filler and hydrophobic character of the polyolefin matrix (Habibi et al. 2008, Poletto et al. 2012, Gallangher and McDonald 2013). Lignocellulosic fillers do not disperse easily in thermoplastic polymers and tend to agglomerate during the compounding process (Poletto et al. 2012). Thus, the low compatibility and low interfacial adhesion lead to composites with low mechanical properties and low thermal stability. To improve interfacial adhesion coupling agents were used (Khonsari et al. 2015, El-Sabbagh et al. 2014). Maleic anhydridegrafted thermoplastic polymers are the most common coupling agent used in WPC (Kim et al. 2007, Cui et al. 2008, Poletto et al. 2014). However, other polar monomers from sustainable resources such 
as itaconic acid and its derivatives have been studied recently (Toro et al. 2007, Palza et al. 2009).

Itaconic acid (methylene butanedioic acid) is a vinyl monomer containing two carboxylic groups, and is obtained through large-scale fermentation of agricultural wastes and carbohydrates such as glucose (Rose and Palkovits 2011). It is a white crystalline unsaturated dicarbonic acid with one carboxyl group conjugated to the methylene group (Willke and Vorlop 2001). Due to its double functionality, itaconic acid and its derivatives offer interesting possibilities as polar functional monomers for the modification of polyolefins and used as coupling agent in composite formulations (Toro et al. 2007, Palza et al. 2009). The utilization of itaconic acid as polar monomer grafted in polyolefins can be considered important because of its carboxylic bifunctionality and also due to the fact that itaconic acid is produced from non-oil based renewable natural resource, i.e., by large scale fermentation of molasses, a by-product from sugar industry (Bruna et al. 2005).

In this way, this work assesses the utilization of polypropylene grafted itaconic acid (PPgIA) as coupling agent in polypropylene (PP) WPC as a friendlier environmental alternative instead of use PP grafted maleic anhydride (PPgMA). The mechanical properties, thermal stability and morphology of the WPC without and with coupling agent were evaluated.

\section{MATERIALS AND METHODS}

\section{Materials}

PP from post consumer food packaging was supplied by Associação dos Recicladores de Caxias do Sul (Caxias do Sul, Rio Grande do Sul/Brazil). The wastes were washed and grounded in a knife mill before use in composite formulations. Wood flour from Pinus elliottii (PIE) was obtained from Madarco Co. (Caxias do Sul, Rio Grande do Sul/Brazil) having particle size between 50-150 $\mu \mathrm{m}$ were dried in a vacuum oven at $105^{\circ} \mathrm{C}$ for $24 \mathrm{~h}$, before use in composite formulations. Two coupling agents were used. PP grafted maleic anhydride (PPgMA) Polybond 3200 supplied by Chemtura Co. Ltd with melt flow index of 10,1 g/min and PP grafted itaconic acid (PPgIA) supplied by Prof. Raúl Quijada (Universidad de Chile). Both coupling agents used contain $1 \mathrm{wt} \%$ of maleic anhydride grafted onto PP. The molecular weight of PPgMA is 42,000 g/mol, while PPgIA presents a molecular weight of 90,000 $\mathrm{g} / \mathrm{mol}$ (Kim et al. 2007, Moncada et al. 2006). The incorporation of each coupling agent in composite formulation as fixed at $2 \mathrm{wt} \%$. Table 1 shows the formulations developed.

Table 1. Formulations developed in this study (wt $\%)$.

\begin{tabular}{|l|c|c|c|}
\hline Sample & PP & PIE & Coupling agent \\
\hline PPr & 100 & 30 & 0 \\
\hline PPr/PIE & 70 & 30 & 0 \\
\hline PPr/PIE/PPgMA & 68 & 30 & 2 \\
\hline PPr/PIE/PPgIA & 68 & 30 & 2 \\
\hline
\end{tabular}

\section{Composite preparation}

Composites were prepared using a co-rotating twin-screw extruder from $\mathrm{MH}$-equipments with $\mathrm{L} /$ $\mathrm{D}=32$ and $\mathrm{D}=20 \mathrm{~mm}$. A screw speed of $200 \mathrm{rpm}$ was used and the nine barrel temperature zones were maintained at $170^{\circ} \mathrm{C}-190^{\circ} \mathrm{C}$. The extruded material was dried in an oven at $80^{\circ} \mathrm{C}$ for $24 \mathrm{~h}$. Specimens were injection molded (HIMACO LH $150-80$ ) at a barrel temperature of $170-180^{\circ} \mathrm{C}$ and mold temperature of $40 \pm 2^{\circ} \mathrm{C}$. 


\section{Mechanical properties measurements}

The flexural tests were performed according to ASTM D790 at a flexural speed of $1.5 \mathrm{~mm} / \mathrm{min}$ using an EMIC DL3000 testing machine. Izod impact strength was determined in a CEAST Resil 25 pendulum using notched specimens according to ASTM D256. Each test value was obtained as the average of at least five independent measurements.

The statistical analysis of variance for composite mechanical properties has been carried out using commercial software (EXCEL). A one-way analysis of variance and t-tests were used to evaluate the statistical difference among groups. Values of $p<0,05$ were considered significant.

\section{Morphological study}

The fiber/matrix interface was investigated by scanning electron microscopy (SEM) analysis, using a Superscan S-550, operating at an accelerating voltage of $15 \mathrm{kV}$. The samples were crio-fractured and the surfaces were sputter-coated with gold.

\section{Thermogravimetric analysis (TGA)}

TGA measurements were carried out using a thermogravimetric analyzer TGA 50-Shimadzu, under constant nitrogen flow $(50 \mathrm{ml} / \mathrm{min})$ from 25 to $700^{\circ} \mathrm{C}$, at a heating rate of $10^{\circ} \mathrm{C} / \mathrm{min}$. Approximately 10 mg of each sample was used.

\section{RESULTS AND DISCUSSIONS}

\section{Mechanical properties}

Considering practical applications, WPC mechanical properties are of major importance (Nachtigall et al. 2007, Dányádi et al. 2010). The adhesion between fiber and matrix in wood flour reinforced thermoplastic composites plays a fundamental role in order to achieve good mechanical properties (Nachtigall et al. 2007, Poletto et al. 2012). As presented in Table 2 the flexural strength of recycled $\mathrm{PP}$ are $33 \mathrm{MPa}$, while composites with $30 \mathrm{wt} \%$ of wood flour presented a flexural strength equal to 32,7 MPa. The statistical analysis revel that no significant differences between flexural strength values were obtained when wood flour was incorporated into the PP matrix. This result indicates that wood flour behaves as filler when incorporated into PP, at least without coupling agent. This occurs because of the chemical incompatibility between the non-polar polyolefin and the higher polar character of the filler, resulting in low interfacial adhesion leading to agglomeration of the wood flour (Nachtigall et al. 2007, Poletto et al. 2012). As consequence, the low adhesion induces the presence of gaps between the fiber and polymer matrix that results in composites with low mechanical properties (Cui et al. 2008). On the other hand, the addition of coupling agents results in composites with better performance. The flexural strength was increased up to $42 \mathrm{MPa}$ and 44,3 MPa for composites with PPgIA and PPgMA, respectively. The addition of PPgIA and PPgMA represents an increase on the flexural strength of approximately $29 \%$ and $35 \%$, respectively, when compared with the WPC without coupling agent. This behaviour can be attributed to the enhanced chemical compatibility between the filler and matrix (Dányádi et al. 2010, El-Sabbagh 2014). The presence of hydroxyl groups on the surface of wood flour may promote the establishment of strong interactions between the coupling agents and the fibers, while the non-polar part of the coupling agents may form entanglements with the polypropylene matrix (Poletto et al. 2012, El-Sabbagh 2014). This results in more stress transfer from the matrix to fibers which causes improved in mechanical properties as observed in Table 2. Toro and coworkers (Toro et al. 2007) also observed an increase in the composite strength when itaconic acid as used as coupling 
agent. According to the authors, a better interaction between the PP matrix and talc or calcium carbonate filler is promoted by the coupling agent, which can indicated the formation of hydrogen bonds between filler and matrix.

Table 2. Mechanical properties of the samples studied.

\begin{tabular}{|l|c|c|c|c|}
\hline Sample & $\begin{array}{c}\text { Flexural strength } \\
(\mathbf{M P a})\end{array}$ & $\begin{array}{c}\text { Flexural } \\
\text { strain } \\
\mathbf{( \% )}\end{array}$ & $\begin{array}{c}\text { Flexural modulus } \\
\mathbf{( M P a})\end{array}$ & $\begin{array}{c}\text { Impact strength } \\
(\mathbf{J} / \mathbf{m})\end{array}$ \\
\hline $\mathrm{PPr}$ & $33,04^{\mathrm{a}}$ & $7,21^{\mathrm{a}}(0,17)$ & $1158^{\mathrm{a}}$ & $42,40^{\mathrm{a}}$ \\
\hline PPr/PIE & $(0,45)$ & $(21)$ & $(2,25)$ \\
\hline PPr/PIE/PPgMA & $32,71^{\mathrm{a}}$ & $4,73^{\mathrm{b}}(0,10)$ & $1929^{\mathrm{b}}$ & $29,34^{\mathrm{b}}$ \\
& $(1,42)$ & $(95)$ & $(0,97)$ \\
\hline PPr/PIE/PPgIA & $44,34^{\mathrm{b}}$ & $4,71^{\mathrm{b}}$ & $2064^{\mathrm{c}}$ & $26,65^{\mathrm{c}}$ \\
& $(0,89)$ & $(0,09)$ & $(31)$ & $(0,92)$ \\
\hline
\end{tabular}

Values for standard deviation are given in parentheses.

Results with the same superscript letter in their respective column are significantly the same.

The WPC material becomes stiffer with addition of wood flour, however the corresponding flexural strain at maximum yield reduces drastically, as presented in Table 2, as a consequence of the reduction of polymer chains mobility imposed by the wood fibers. It was verified that flexural modulus increased from $1158 \mathrm{MPa}$ to $1929 \mathrm{MPa}$, when compared PP matrix and PP/PIE sample. This is a common behavior when rigid fillers are incorporated into softer polymer matrices (Rosa et al. 2009, Nygård et al. 2008) since wood fibers presented higher modulus than PP (Rosa et al. 2009). WPC treated with PPgMA showed a slight higher flexural modulus than WPC treated with PPgIA, as presented in Table 2.

The results in Table 2 show that impact strength decreased with the addition of wood flour for all WPC developed. This may be explained by the fact that during impact cracks are expected to travel trough the matrix as well as trough the interface. Introduction of reinforcement fillers such as wood fibers will introduce weak interfacial regions and stress concentration at fiber ends that can reduce the impact strength (Nygård et al. 2008). In addition the wood fibers are also believed to reduce the polymer chain mobility and thereby reduce the composite ability in absorb energy during fracture propagation leading to lower impact strength values (Adhikary et al. 2008, Nygård et al. 2008).

\section{Morphological characterization}

Figure 1(a) show the SEM micrograph of the composite without coupling agent, PP/PIE sample, while Figure 1(b) presented the composites treated with PPgIA. From Figure 1(a) is clearly evident the presence of fiber pulled-out trace and bigger gaps between the wood flour and matrix, which is evidence of weak interfacial adhesion at the interface (Kim et al. 2007, Habibi et al. 2008). Weak interfacial adhesion easily promote the complete fiber debonding from the polypropylene matrix (Kim et al. 2007) which results in the low flexural strength observed for PP/PIE sample on the mechanical tests. On the other hand, the SEM micrograph of PPgIA treated composite reveals the strong bonding and paucity of fiber pulled-out traces from the matrix. This result demonstrated that the addition of PPgIA treatment in composite formulation provides strong interfacial adhesion and good wetting, as 
evidence by almost complete absence of holes around the matrix (Kim et al. 2007, Poletto et al. 2012).
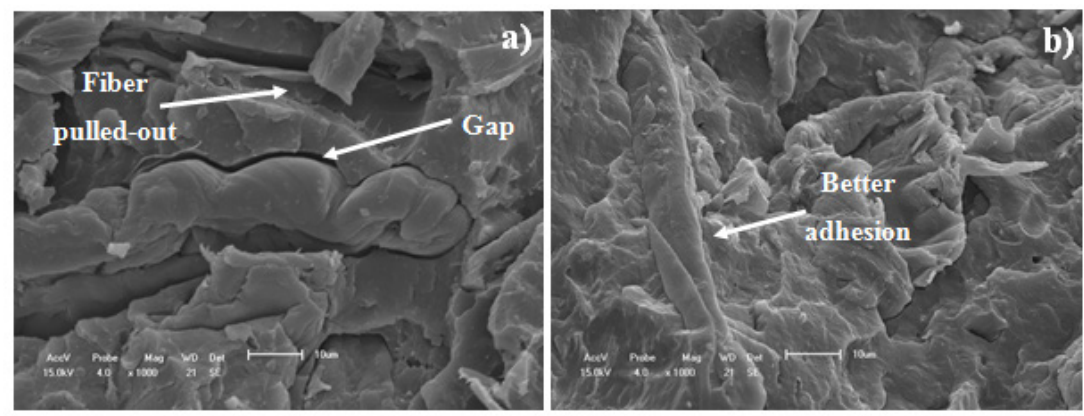

Figure 1. SEM micrographs of the composites without coupling agent (a) and treated with PPgIA (b).

\section{Thermogravimetric analysis}

The thermogravimetric results of PPr, PIE, and WPCs show distinct process of weight loss occurring at different temperatures, as showed in Figure 2(a). For PP there is only one weight loss process, while the wood flour presented two main weight loss processes, as can be seen in Figure 2(b).
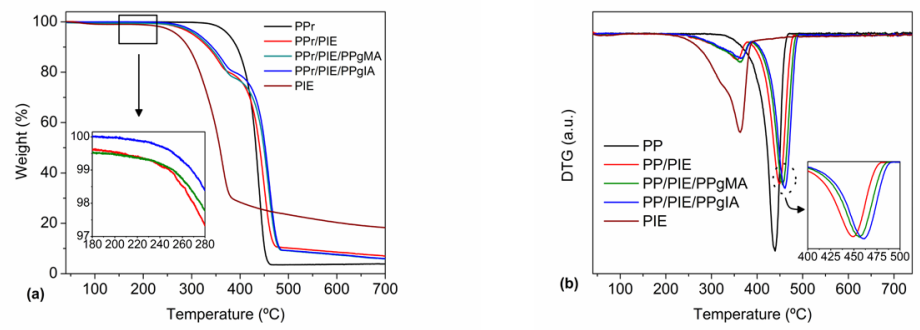

Figure 2. Thermogravimetric curves (a) and the first derivative curves (DTG) (b) of PP, PIE and WPC studied.

From the thermogravimetric curve it is feasible to observe that the wood flour shows a small weight loss at around $100^{\circ} \mathrm{C}$ due to the water devolatilization. The next weight loss process occurs at $200^{\circ} \mathrm{C}$ and is associated with the initial thermal degradation of main wood components and compounds with low molecular mass (Araújo et al. 2008). The maximum rate of weight loss for wood flour occurs at $367^{\circ} \mathrm{C}$, as presented in Table 3 . The PPr initiates the degradation process at around $350^{\circ} \mathrm{C}$, with the maximum weight loss rate at $439^{\circ} \mathrm{C}$. 
Table 3. Several temperatures and residue at $700^{\circ} \mathrm{C}$ for samples studied.

\begin{tabular}{|l|c|c|c|c|}
\hline Sample & $\mathbf{T}_{\mathbf{i}}\left({ }^{\mathbf{}} \mathbf{C}\right)$ & $\mathbf{T p}_{\mathbf{1}}\left({ }^{\mathbf{}} \mathbf{C}\right)$ & $\mathbf{T p}_{\mathbf{2}}\left({ }^{\circ} \mathbf{C}\right)$ & $\begin{array}{c}\text { Residue at } \\
\mathbf{7 0 0}^{\circ} \mathbf{C}(\mathbf{\%})\end{array}$ \\
\hline PPr & 367 & ---- & 440 & 3,9 \\
PIE & 252 & 322 & 367 & 18,3 \\
\hline PPr/PIE & 284 & 353 & 451 & 7,0 \\
\hline PPr/PIE/PPgMA & 290 & 367 & 459 & 5,9 \\
\hline PPr/PIE/PPgIA & 298 & 370 & 462 & 6,0 \\
\hline
\end{tabular}

The initial weight loss temperature $T_{i}$, considered in this work as the temperature when the sample loses $3 \%$ of its weight, for the treated composites are higher than composite without coupling agent, as can be seen in Table 3. The addition of PPgMA increases the T. value in $6^{\circ} \mathrm{C}$, while the incorporation of PPgIA causes an improve of approximately $14^{\circ} \mathrm{C}$ in the composite thermal stability when compared with the composite without coupling agent, as showed in detail in Figure 2(a). Thereby, the composite compatibilised with PPgMA is less stable than composite with PPgIA. In addition the composite treated with PPgMA present a maximum rate of weight loss at $459^{\circ} \mathrm{C}$ while the composite treated with PPgIA as a maximum rate of weight loss at about $462^{\circ} \mathrm{C}$. The maximum rate of weight loss is $9^{\circ} \mathrm{C}$ and $11^{\circ} \mathrm{C}$ higher than the maximum rate of weight loss of the non-treated composite, as showed in detail in Figure 2(b), indicating the improved in thermal stability caused by the coupling agents. The residue at $700^{\circ} \mathrm{C}$ is almost the same for the two treated composites. Sailaja and Seetharamu (2008), used itaconic acid grafted low density polyethylene (LDPE) as coupling agent for LDPE plasticized tapioca starch blends. The authors also observed that the coupling agent improves the blend thermal stability, and they attribute this improvement to the interactions that occurs between the blend components when itaconic acid grafted LDPE was used.

\section{CONCLUSIONS}

The usage of PPgIA as coupling agent in polypropylene wood flour composites showed similar mechanical properties to the composites treated with PPgMA. The SEM micrographs confirm the interfacial adhesion improved caused by PPgIA. On the other hand, the thermogravimetric results indicated that PPgIA caused a higher increased in composite thermal stability than PPgAM. Thus, PPgIA as potential to replace PPgAM as coupling agent in composites reinforced with wood flour. Nevertheless, novel polymers obtained from biomass, such as itaconic acid, attracted increasing attention of the scientific community and industries to replace polymers obtained from non renewable resources and thereby, future investigations will certainly pinpoint to a wider range of applications for materials obtained from biomass.

\section{ACKNOWLEDGEMENTS}

The author is grateful to Associação dos Recicladores de Caxias do Sul, Madarco Co., Prof. Raúl Quijada (Universidad de Chile) and Chemtura Co. for supplying materials. 


\section{REFERENCES}

Adhikary, K.B.; Pang, S.; Staiger, M.P.2008. Dimensional stability and mechanical behaviour of wood-plastic composites based on recycled and virgin high-density polyethylene (HDPE). Composites Part B 39: 807-815.

Araújo, J.R.; Waldman, W.R.; De Paoli, M.A. 2008. Thermal properties of high density polyethylene composites with natural fibers: coupling agent effect. Polymer Degradation and Stability 93: 1770-1775.

Bruna, J.; Yazdani-Pedram, M.; Quijada, R. Valentín, J.L.; López- Manchado, M.A. 2005. Melt grafting of itaconic acid and its derivatives onto an ethylene-propylene copolymer. Reactive \& Functional Polymers 64: 169-178.

Cui, Y.; Lee, S.; Noruziaan, B.; Cheung, M.; Tao, J. 2008. Fabrication and interfacial modification of wood/recycled plastic composite materials. Composites Part A 39: 655-661.

Dányádi, L.; Móczó, J.; Pukánszky, B. 2010. Effect of various surface modifications of wood flour on the properties of PP/wood composites. Composites Part A 41: 199-206.

El-Sabbagh, A. 2014. Effect of coupling agent on natural fibre/polypropylene composites on mechanical and thermal behaviour. Composites Part B 57: 126-135.

Fabiyi, J.S.; McDonald, A.G. 2014. Degradation of polypropylene in naturally and artificially weathered plastic matrix composites. Maderas-Cienc Tecnol 16: 275-290.

Gallagher, L.W.; McDonald, A.G. 2013. The effect of micron sized fibers in wood plastic composites. Maderas-Cienc Tecnol 15: 357-374.

Habibi, Y.; El-Zawawy, W.K.; Ibrahim, M.M.; Dufresne, A. 2008. Processing and characterization of reinforced polyethylene composites made with lignocellulosic fibers from Egyptian agro-industrial residues. Composites Science and Technology 68: 1877-1885.

Khonsari, A.; Taghiyari, H.R.; Karimi, A.; Tajvidi, M. 2015. Study on the effect of wood flour geometry on physical and mechanical properties of wood-plastic composites. Maderas-Cienc Tecnol 17: $545-558$.

Kim, H.S.; Lee, B.H.; Choi, S.W.; Kim, S.; Kim, H.J. 2007. The effect of types of maleic anhydride-grafted polypropylene (MAPP) on the interfacial adhesion properties of bio-flour-filled polypropylene composites. Composites Part A 38: 1473-1482.

Moncada, E.; Quijada, R.; Lieberwirth, I.; Yazdani-Pedram, M. 2006. Use of PP grafted with itacoic acid as a new compatibilizer for PP/clay nanocomposites. Macromolecular Chemistry and Physics 207: 1376-1386.

Nachtigall, S.M.B.; Cerveira, G.S.; Rosa, S.M.L. 2007. New polymeric-coupling agent for polypropylene/wood-flour composites. Polymer Testing 26: 619-628.

Nygård, P.; Tanem, B.S.; Karlsen, T.; Brachet, P.; Leinsvang, B. 2008. Extrusion-based wood fibre-PP composites: wood powder and pelletized wood fibres- a comparative study. Composites Science and Technology 68: 3418-3424.

Palza, H.; Vergara, R.; Yazdani-Pedram, M.; Quijada, R. 2009. Polypropylene/clay nanocomposites: effect of different clays and compatibilizers on their morphology. Journal of Applied Polymer Science 112: 1278-1286. 
Poletto, M.; Zeni, M.; Zattera, A.J. 2012. Effects of wood flour addition and coupling agent content on mechanical properties of recycled polystyrene/wood flour composites. Journal of Thermoplastic Composite Materials 25: 821-833.

Poletto, M.; Zattera, A.J.; Santana, R.M.C. 2014. Effect of natural oils on the stability and degradation kinetics of recycled polypropylene wood flour composites. Polymer Composites 10: 19351942.

Rosa, S.M.L.; Santos, E.F.; Ferreira, C.A.; Nachtigall, S.M.B. 2009. Studies on the properties of rice-husk-filled-PP composites - effect of maleated PP. Materials Research 12: 333-338.

Rose, M.; Palkovits, R. 2011. Cellulose-based sustainable polymers: state of the art and future trends. Macromolecular Rapid Communications 32: 1299-1311.

Sailaja, R.R.N.; Seetharamu, S. 2008. Itaconic acid-grafed LDPE as compatibilizer for LDPE-plasticized Tapioca starch blends. Reactive \& Functional Polymers 68: 831-841.

Toro, P.; Quijada, R.; Peralta, R.; Yazdani-Pedram, M. 2007. Influence of grafted polypropylene on the mechanical properties of mineral-filled polypropylene composites. Journal of Applied Polymer Science 103: 2343-2350.

Willke, T.; Vorlop, K.D. 2001. Biotechnological production of itaconic acid. Applied Microbiology and Biotechnology 56: 289-295. 